\title{
KOREOGRAFI GARONTO' EANAN: VISUALISASI KERBAU DALAM KEHIDUPAN MASYARAKAT TORAJA
}

\author{
Robby Somba \\ Jurusan Tari, Fakultas Seni Pertunjukan, ISI Yogyakarta \\ Email: robbysomba99@gmail.com
}

\section{RINGKASAN}

Garonto' Eanan adalah karya tari yang terinspirasi tentang hewan kerbau dalam kehidupan masyarakat Toraja, terkhusus dalam upacara pemakaman Rambu Solo'. Kerbau merupakan hewan yang sangat penting bagi masyarakat Toraja untuk menandai status sosial seseorang. Dalam upacara Rambu Solo' kerbau wajib dikurbankan untuk memberikan penghormatan terakhir serta menjadi bekal kubur dan harta bagi orang yang meninggal.

Tema tari Garonto' Eanan adalah kekuatan dan kebersamaan. Koreografi ini disajikan dengan pola large group composition, ditarikan tujuh penari laki-laki sebagai presentasi hewan kerbau, dan 12 penari Ma'badong. Gerak yang disajikan berpijak pada gerak tari tradisional Toraja, dikembangkan sesuai dengan ketubuhan penata tari. Karya tari Garonto'Eanan menyajikan tiga bagian. Bagian pertama menghadirkan satu penari laki-laki sebagai pengantar karya yang menyajikan bentuk gerak tradisional Toraja serta bentuk simbolis dari hewan Kerbau. Bagian kedua menyajikan hasil eksplorasi gerak terhadap makna dan nilai Kerbau dalam masyarakat Toraja. Bagian ketiga sekaligus bagian akhir dalam karya ini, memvisualisasikan suasana Rambu Solo' dan gambaran Kerbau saat tengah beradu, digarap dalam pola garap duet. Bagian ini juga menghadirkan penari Ma'badong. Musik pengiring koreografi ini disajikan dalam format musik live. Rias Busana yang digunakan dalam tari “Garonto' Eanan” yakni rias karakter, sedangkan desain kostum, baju tanpa lengan dan celana pendek.

Kata kunci : Rambu Solo', Kerbau, Toraja 


\section{ABSTRACT}

Garonto' Eanan is the title of traditional dance telling a story about buffalos in the Toraja community life, especially during the funeral ceremony Rambu Solo'. Buffalos are functioned to mark someone's social status, making it as one of the most notable animals for the Toraja community. It is obligatory to make buffalos as one of the offerings for the ceremony Rambu Solo'. Buffalo offering aims to express the last admiration and tribute for the dead.

The traditional dance Garonto' Eanan recites power and togetherness as the themes. The choreography is performed by seven male dancers as the buffalo representation and twelve Ma'badong dancers by applying a large group composition pattern. Furthermore, the choreography was arranged by referring to the traditional dancing choreography of Toraja and developed according to the intention of choreographers. The traditional dance Garonto' Eanan presents three segments. The first segment presents one male dancer performing the dance introduction. He presents traditional choreography of Toraja and portrays buffalos symbolically. The second segment presents the results of choreographic explorations in both meaning and values of buffalos for the Toraja community. The third or the last segment visualizes the atmosphere of Rambu Solo' and illustrates fighting buffaloes performed by the dancers in pairs. The segment also presents Ma'badong dancers. Moreover, there is a live musical performance accompanying the dance performance. Meanwhile, the Garonto' Eanan dancers apply the character makeup style; whereas for their costume, they wear a sleeveless shirt and short pants.

Keywords: Rambu Solo', Buffalo, Toraja 


\section{PENDAHULUAN}

Upacara Rambu Solo' merupakan upacara pemakaman yang bertujuan untuk menghormati dan menghantarkan arwah orang yang meninggal menuju alam roh (puya).

Upacara ini merupakan upacara terpenting, karena dalam pandangan hidup masyarakat Toraja kematian adalah merupakan titik permulaan kehidupan baru di alam lain. Bagi masyarakat Toraja, orang yang baru saja meninggal dunia belum bisa dikatakan bahwa orang itu benar-benar mati, tetapi masih dianggap sebagai orang yang sakit ( $T o$ Makula). Untuknya masih disajikan makanan dan minuman kesukaannya seperti waktu ia masih hidup. ${ }^{1}$ Orang yang meninggal bisa dikatakan betul-betul mati apabila upacara pemakaman mulai dilangsungkan.

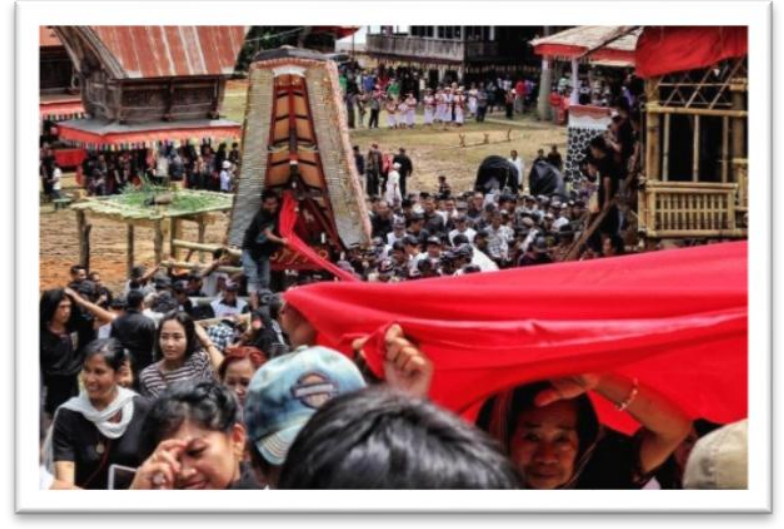

Gambar 1. Masyarakat ikut mengantarkan peti jenazah dari tempat kediaman menuju Rante

(lapangan), saat pelaksanaan ritual Rambu Solo'

(Foto: Abun Pasanggang, Oktober 2017)

Menurut kepercayaan Aluk Todolo, mati adalah suatu proses perubahan status dari manusia yang hidup berubah menjadi manusia roh di alam baka. ${ }^{2}$ Diyakini bahwa kehidupan jasmani di bumi akan tetap sama dengan kehidupan di alam baka, hanya saja tidak dapat dilihat dan diraba secara fisik. Orang yang meninggal harus dirawat dan diberi perlakuan yang baik seperti merawat orang yang masih hidup dengan mempersiapkan semua kelengkapan dan keperluannya untuk dipakai oleh roh yang meninggal di puya.

Bekal dan perlengkapan utama yang akan dipergunakan di alam baka yaitu, seluruh peralatan upacara, hewan kurban, pakaianpakaian serta harta benda yang dimasukkan ke dalam bungkusan mayat orang yang

2 Hc.L.T. Tangdilintin, 2014, Toraja dan Kebudayaannya, Toraja Utara, Lembaga Kajian dan Penulisan Sejarah Budaya Sulawesi Selatan, p.92
Hc.L.T. Tangdilintin, 2014, Toraja dan
Kebudayaannya, Toraja Utara, Lembaga Kajian dan Penulisan Sejarah Budaya Sulawesi Selatan, p.91 
meninggal. ${ }^{3}$ Hal ini merupakan kewajiban karena semua harta benda dan hewan-hewan itu mempunyai roh seperti manusia dan akan dimiliki juga oleh roh manusia di alam baka. Itulah sebabnya masyarakat Toraja harus mengumpulkan harta benda sebanyakbanyaknya pada masa hidupnya dengan tujuan bahwa sisa dari harta yang dimakan atau digunakan selama dia masih hidup akan dipergunakan untuk upacara pemakamannya kelak. ${ }^{4}$ Hewan kurban seperti babi, kerbau, dan ayam yang dipersembahkan untuk arwah orang yang meninggal sebagai bukti penghormatan, nantinya akan menentukan kedudukan arwah yang disebut Tomembali Puang. Menurut kepercayaan Aluk Todolo, seseorang yang akan datang ke Puya dan tidak membawa bekal kurban dari bumi tidak dapat diterima dengan wajar oleh roh-roh yang terlebih dulu menuju atau sudah ada di puya. $^{5}$

Upacara Rambu Solo' dilaksanakan karena masyarakat meyakini bahwa

\footnotetext{
3 Hc.L.T. Tangdilintin, 2014, Toraja dan Kebudayaannya, Toraja Utara, Lembaga Kajian dan Penulisan Sejarah Budaya Sulawesi Selatan, p.92 ${ }^{4}$ Hc.L.T. Tangdilintin, 2014, Toraja dan Kebudayaannya, Toraja Utara, Lembaga Kajian dan Penulisan Sejarah Budaya Sulawesi Selatan, p.92 ${ }^{5}$ Hc.L.T. Tangdilintin, 2014, Toraja dan Kebudayaannya, Toraja Utara, Lembaga Kajian dan Penulisan Sejarah Budaya Sulawesi Selatan, p.93. ${ }^{6}$ Wawancara dengan bapak Arnold Souisa, 27 tahun. Guru Bahasa dan Seni di SMK Tagari Rantepao, pada hari Minggu, 6 Agustus 2017, Di Rantepao, Toraja Utara.

${ }^{7}$ Wawancara dengan bapak Arnold Souisa, 27 tahun. Guru Bahasa dan Seni di SMK Tagari Rantepao, pada hari Minggu, 6 Agustus 2017, Di Rantepao, Toraja Utara.
}

kehidupan di puya layaknya seperti kehidupan di bumi, hanya saja serba terbalik, karena dari yang fana (duniawi) ke yang baka (roh). ${ }^{6}$ Keyakinan bahwa kehidupan di alam baka juga seperti kehidupan di bumi, sehingga ketika masyarakat Toraja meninggal, dilakukanlah pengorbanan. ${ }^{7}$ Pengorbanan yang dimaksudkan di sini intinya adalah darah, karena di dalamnya ada nyawa. Ketika darah tertumpahkan, otomatis nyawa terputus dari tubuh fisiknya, sehingga nyawa itu kembali kepada sang pencipta yang memberikan kehidupan. ${ }^{8}$ Ketika nyawa terputuskan melalui tumpahnya darah, maka nyawa akan kembali menjadi roh. ${ }^{9}$ Begitu pula dengan orang yang meninggal, rohnya dipercaya berangkat bersama-sama dengan roh hewan yang dikurbankan, apakah itu hewan kerbau, babi, anjing, atau ayam. ${ }^{1010}$

Dari berbagai macam hewan kurban yang dipersembahkan, hewan kerbaulah yang menjadi pokok harta benda ( garonto $^{\prime}=$ pokok, eanan $=$ harta benda). ${ }^{11}$ Kerbau yang

\footnotetext{
${ }^{8}$ Wawancara dengan bapak Arnold Souisa, 27 tahun. Guru Bahasa dan Seni di SMK Tagari Rantepao, pada hari Minggu, 6 Agustus 2017, Di Rantepao, Toraja Utara.

${ }^{9}$ Wawancara dengan bapak Arnold Souisa, 27 tahun. Guru Bahasa dan Seni di SMK Tagari Rantepao, pada hari Minggu, 6 Agustus 2017, Di Rantepao, Toraja Utara

${ }^{10}$ Wawancara dengan bapak Arnold Souisa, 27 tahun. Guru Bahasa dan Seni di SMK Tagari Rantepao, pada hari Minggu, 6 Agustus 2017, Di Rantepao, Toraja Utara.

${ }^{11}$ Hc.L.T. Tangdilintin, 2014, Toraja dan Kebudayaannya, Toraja Utara, Lembaga Kajian dan Penulisan Sejarah Budaya Sulawesi Selatan, p.234.
} 
dikorbankan harus disesuaikan dengan kasta orang yang meninggal, dan menghitung kemampuan penyediaan hewan yang akan dikurbankan. Masyarakat Toraja mengenal susunan kasta dan jumlah hewan yang akan dikurbankan yaitu:

\section{a. Tana' Bulaan yaitu kasta bangsawan - 24 ekor kerbau. \\ b. Tana' Bassi yaitu kasta bangsawan menengah -6 ekor kerbau. \\ c. Tana Karurung yaitu kasta rakyat orang merdeka - 2 ekor kerbau. \\ d. Tana' Kua - Kua yaitu kasta hamba - 1 ekor babi. ${ }^{12}$}

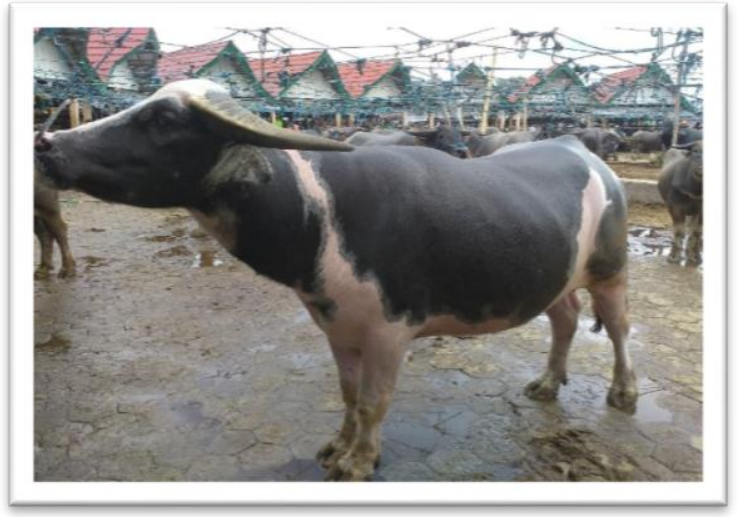

Gambar 2. Kerbau Lotong Boko' (Foto: Robby Somba, Februari 2018)

Kerbau atau tedong dalam dasar pemikiran orang Toraja merupakan pokok harta benda karena kerbau adalah hewan paling penting dalam kehidupan sosial masyarakat. Kerbau bagi masyarakat Toraja tidak dapat dipisahkan dari kehidupan sehari-hari. Selain

\footnotetext{
${ }^{12}$ Seno Paseru H., M.Si, 2004, Aluk Todolo Toraja Upacara Pemakaman Masa Kini Masih Sakral, Salatiga, Widya Sari Press.

${ }^{13}$ Wawancara dengan Bapak Arnold Souisa 27 tahun. Guru Bahasa dan Seni di SMK Tagari Rantepao, Pada
}

sebagai hewan untuk memenuhi kebutuhan hidup sosial, ritual maupun kepercayaan tradisional, kerbau juga menjadi alat transaksi dan takaran status sosial seseorang. Dari sisi sosial, kerbau merupakan harta yang bernilai tinggi bagi pemiliknya. Tidak mengherankan bila orang Toraja sangat dekat dengan kerbau mereka. Hal ini dapat dilihat dari percakapan sehari-hari, pada saat hendak bertransaksi, mengadakan pesta, atau dalam praktik keagamaan.

Kerbau dalam upacara Rambu Solo', secara religius diyakini sebagai bekal kubur yang menjadi hak milik di puya. ${ }^{13}$ Jika orang yang meninggal adalah pria dari kasta bangsawan, maka dalam pelaksanaan Rambu Solo' akan dihadirkan tarian Pa'randing yang penarinya harus seorang laki-laki dengan menggunakan hiasan kepala menyerupai tanduk kerbau. Akan tetapi jika yang meninggal adalah wanita maka tarian tersebut tidak dapat dihadirkan. Makna kerbau dari segi sosial yang pertama adalah gengsi, semakin banyak mengurbankan hewan kerbau maka semakin 'terpandang' orang tersebut di masyarakat. ${ }^{14}$ Makna kedua tentang kebersamaan dalam ikatan keluarga, setiap keluarga membawakan hewan atau harta yang lainnya akan menjadi hutang, tetapi

hari Minggu, 6 Agustus 2017, Di Rantepao, Toraja Utara.

14 Wawancara dengan Bapak Arnold Souisa 27 tahun. Guru Bahasa dan Seni di SMK Tagari Rantepao, Pada hari Minggu, 6 Agustus 2017, Di Rantepao, Toraja Utara. 
melalui media itulah kita saling silahturahmi. ${ }^{15}$

Ketika kerbau selesai disembelih kemudian dagingnya dibagi-bagikan kepada masyarakat yang hadir. ${ }^{16} \mathrm{Hal}$ ini sudah menjadi kewajiban pihak keluarga karena keluarga yang mengadakan upacara adat juga pernah mendapatkan bagian dari pesta adat orang lain, begitu juga sebaiknya apabila kita sedang menyelenggarakan upacara adat kita juga wajib membalas apa yang sudah kita terima dari orang lain, dan dibagikan juga kepada orang yang tidak mampu. ${ }^{17}$ Di sisi lain, makna kerbau dalam nilai ekonomi di jaman sekarang, menjadi komoditi andalan dalam masyarakat Toraja, sehingga perputaran ekonomi di Toraja termasuk dinominasi jual beli hewan khususnya kerbau dan babi untuk upacara Rambu Solo' ${ }^{18}$

Masyarakat Toraja meyakini bahwa kerbau adalah kendaraan bagi arwah menuju puya (dunia arwah, atau akhirat). Kerbau pun memiliki kedudukan unik bagi masyarakat Toraja. Ia diternakkan untuk dipakai sebagai alat pembajak sawah, sekaligus dianggap hewan sakral, simbol dan status sosial. Bagi masyarakat Toraja, hewan kerbau dimaknai sebagai persembahan tertinggi bagi yang meninggal, melalui ritual Rambu Solo'.

\footnotetext{
15 Wawancara dengan Bapak Arnold Souisa 27 tahun. Guru Bahasa dan Seni di SMK Tagari Rantepao, Pada hari Minggu, 6 Agustus 2017, Di Rantepao, Toraja Utara.

${ }^{16}$ Wawancara dengan Bapak Arnold Souisa 27 tahun. Guru Bahasa dan Seni di SMK Tagari Rantepao, Pada hari Minggu, 6 Agustus 2017, Di Rantepao, Toraja Utara
}

Salah satu ritual penting dalam Rambu Solo' adalah penyembelihan hewan kerbau.

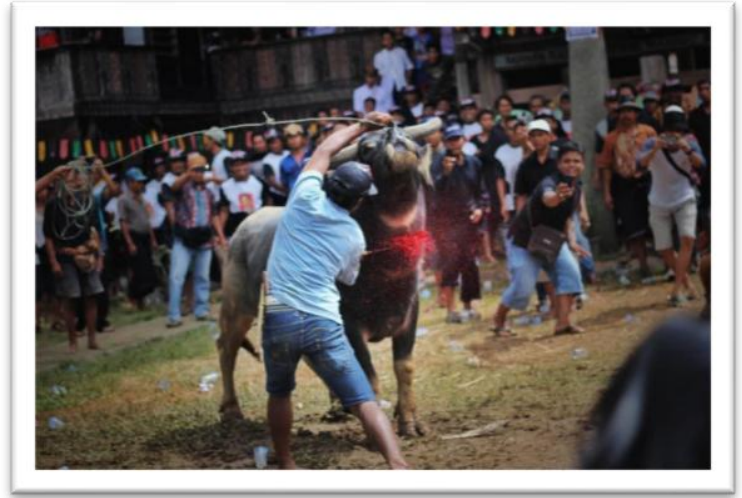

Gambar 3. Penyembelihan Kerbau (Foto: Abun Pasanggang, Oktober 2017)

Pelaksanaan Rambu Solo' mengekspresikan atau mencerminkan nilai kebersamaan masyarakat Toraja. Demikian juga dengan penyembelihan hewan kurban yang dimaksudkan sebagai persembahan (bekal kubur) bagi orang yang meninggal, menunjukkan religiusitas masyarakat Toraja. Dalam upacara Rambu Solo' ini, biasanya kerbau yang diadu adalah kerbau-kerbau yang dianggap cukup kuat, artinya tidak semua kerbau diadu. Jumlah kerbau yang dikurbankan, aksi adu kerbau, dan kehadiran kerbau secara fisik menunjukkan adanya makna kekuatan (kekuatan status sosial

\footnotetext{
17 Wawancara dengan bapak Arnold Souisa 27 tahun. Guru Bahasa dan Seni di SMK Tagari Rantepao, Pada hari Minggu, 6 Agustus 2017, Di Rantepao, Toraja Utara.

${ }^{18}$ Wawancara dengan Arnold Souisa 27 tahun. Guru Bahasa dan Seni di SMK Tagari Rantepao, pada hari Minggu, 6 Agustus 2017, di Rantepao, Toraja Utara.
} 
keluarga yang berduka dan kekuatan kerbau secara fisik).

Dari paparan ini disimpulkan, bahwa hewan kerbau memiliki kedudukan penting serta menjadi pokok harta benda bagi masyarakat Toraja. Dari seringnya terlibat langsung dalam upacara Rambu Solo' dan mengamati fenomena-fenomena yang terjadi, maka diketahui bahwa ada banyak jenis hewan kerbau yang dikurbankan. Penata tari tertarik untuk menciptakan suatu karya tari yang bersumber dari ritual Rambu Solo', yang menyiratkan akan makna kebersamaan dan kekuatan.

\section{PEMBAHASAN}

\section{A. Kerangka Dasar Pemikiran}

Karya tari Garonto' Eanan ini memvisualisasikan kekuatan kerbau dan kebersamaan masyarakat Toraja dalam ritual Rambu Solo'. Untuk mewujudkan tema dari karya ini, maka hal yang harus dilakukan adalah: 1) menggunakan penari berjenis kelamin laki-laki untuk bisa menyampaikan tentang makna kekuatan kerbau melalui gerakan henjutan kaki. 2) dalam masyarakat Toraja dikenal tujuh jenis kerbau yaitu Bonga Saleko, Pudu', Bonga Ulu, Bonga Sori, Todi, Sambao' dan Bulan, mengarahkan pada penetapan jumlah tujuh

\footnotetext{
19 Jacqueline Smith, Dance Composition A Practical Guide For Teachers, 1976, Komposisi Tari : Sebuah Petunjuk Praktis Bagi Guru, terjemahan Ben Soeharto, Yogyakarta, Ikalasti, 1985, p.20.
}

penari. 3) Motif gerak dalam karya ini berpijak pada gerak-gerak tari tradisional Toraja yaitu gerak tari Pa'gellu dan gerak tari Pa'randing. Serta menghadirkan elemen gerak tari Ma'badong untuk memberikan kesan dramatik Rambu Solo'. Adapun aspekaspek untuk mendukung penyampaian gagasan tersebut ke dalam sebuah karya tari yaitu: 1) kostum dan tata rias busana lebih dominan berwarna hitam dan diberi sentuhan gambar motif khas Toraja. 2) musik iringan yang disajikan yaitu musik iringan dalam format live yang berpijak pada musik tradisional Toraja dengan instrumen utamanya yaitu gendang dan suling, yang dipadukan dengan instrumen lain.

\section{B. Konsep Dasar Tari}

\section{Rangsang Tari}

Rangsang tari dapat didefinisikan sebagai sesuatu yang membangkitkan pikir, atau semangat, atau mendorong kegiatan. ${ }^{19}$ Munculnya ide dalam menciptakan karya seni berawal dari adanya rangsang. Rangsang menjadi hal dasar yang menggerakkan pikir dan fisik untuk mencipta gerak maupun tarian. Rangsang bagi komposisi tari dapat berupa auditif, visual, gagasan, rabaan atau kinestetik. $^{20}$ Karya tari Garonto' Eanan diawali adanya rangsang visual yaitu

\footnotetext{
20 Jacqueline Smith, Dance Composition A Practical Guide For Teachers, 1976, Komposisi Tari : Sebuah Petunjuk Praktis Bagi Guru, terjemahan Ben Soeharto, Yogyakarta, Ikalasti, 1985, p.20.
} 
kehadiran kerbau sebagai hewan kurban dalam ritual Rambu Solo', rangsang ini selanjutnya melahirkan ide yaitu pemaknaan dari aktivitas upacara yang dipersepsikan sebagai makna kebersamaan dan kekuatan.

Sebagai generasi muda masyarakat Toraja, penata merasa berkewajiban untuk ikut menjaga dan melestarikan budaya tradisi yang ada. Dengan penciptaan karya ini Garonto' Eanan penata ingin menunjukkan niat tersebut, dan berharap generasi muda lainnya dapat mengikuti dengan cara berbeda sesuai pengetahuan dan pengalaman masingmasing.

\section{Tema Tari}

Tema dipandang sebagai bingkai besar yang membatasi suatu karya tari. Dengan adanya tema maka seorang penata tari mempunyai batasan atau landasan dasar yang digarap menjadi suatu bentuk koreografi. Adapun tema yang diusung ialah tentang makna kekuatan kerbau sebagai hewan kurban dan kebersamaan masyarakat Toraja dalam ritual Rambu Solo'. Hal ini dilakukan untuk menarik perhatian generasi muda agar tidak mengabaikan budaya yang sudah ada dan semakin inovatif dalam berkarya dengan memanfaatkan tradisi budaya sendiri.

\section{Judul}

Judul adalah komponen kecil namun sangat penting dalam sebuah karya. Melalui judul hendaknya telah tersampaikan secara tersurat dan tersirat apa yang akan ditampilkan dalam karya tersebut. Pemilihan judul bahkan penulisan judul yang unik juga menjadi daya tarik tersendiri bagi para penikmat yang akan menyaksikan suatu karya tari. Karya tari ini diberi judul Garonto' Eanan yang artinya "kerbau pokok harta benda". Hewan kerbau mempunyai makna dan nilai tinggi sebagai persembahan yang terbaik bagi para leluhur masyarakat Toraja.

\section{Bentuk dan Cara Ungkap}

Koreografi berjudul Garonto' Eanan ini menggunakan bentuk koreografi kelompok dengan tujuh penari laki-laki. Penggunaan tujuh penari dalam karya ini berkaitan dengan jumlah tujuh jenis kerbau yang ada dalam masyarakat Toraja. Selanjutnya, beberapa motif gerak tari Ma'badong (tarian kedukaan yang melantunkan syair-syair yang berisi doa dan harapan), akan diolah dan dihadirkan untuk menciptakan suasana dramatik Rambu Solo'. Dengan adanya elemen tari Ma'badong, serta pengekspresian makna dan nilai-nilai kerbau sebagai hewan kurban dengan cara memanfaatkan gerak-gerak tari tradisional ke dalam garap tari kelompok, maka dapat dikatakan bahwa karya tari Garonto' Eanan ini menggunakan bentuk tari dramatik dengan mode penyajian atau cara ungkap simbolis. Smith dalam buku Dance Composition $A$ Practical Guide For Teachers terjemahan oleh 
Ben Suharto Komposisi Tari, Sebuah Petunjuk

Praktis bagi Guru menjelaskan, bahwa tari dramatik akan memusatkan perhatian pada sebuah kejadian atau suasana yang tidak menggelarkan cerita. $^{21}$ Konsep karya tari Garonto' Eanan memiliki tiga bagian yaitu bagian introduksi atau bagian satu ditarikan oleh penari tunggal sebagai pengantar dengan menunjukkan motif-motif yang ditarikan dalam garap inti. Bagian dua ditarikan tujuh penari dengan pola rampak simultan dan saling mengisi simultan yang akan mengekspresikan kebersamaan dan kekuatan kerbau sebagai hewan kurban dalam Rambu Solo'. Bagian tiga dimulai dengan adegan adu kerbau hingga menuju adegan akhir menampilkan tarian Ma'badong.

\section{Konsep Garap Tari}

\section{Gerak}

Gerak adalah bahasa komunikasi dalam tari, gerak juga merupakan elemen dasar dalam koreografi. ${ }^{22}$ Gerak dapat diartikan sebagai tenaga yang mengalir dalam ruang dan waktu. Elemen dasar gerak adalah tenaga, ruang, dan waktu. Ketiga hal pokok ini tidak dapat dipisahkan, keseluruhannya menjadi satu keutuhan dalam membangun

\footnotetext{
${ }^{21}$ Jacqueline Smith, Dance Composition A Practical Guide For Teachers, 1976, Komposisi Tari : Sebuah Petunjuk Praktis Bagi Guru, terjemahan Ben Soeharto, Yogyakarta, Ikalasti, 1985, p.27

22 Jacqueline Smith, Dance Composition A Practical Guide For Teachers, 1976, Komposisi Tari : Sebuah
}

gerak. Konsep gerak yang digunakan dalam karya tari Garonto' Eanan adalah bentuk gerak yang dikembangkan dari beberapa motif tari tradisional Toraja yaitu tari Pa'gellu dan tari Pa'randing. Dari tari Pa'gellu, gerak henjutan tubuh dengan sikap kaki satu menapak dan kaki satunya menjinjit dengan kualitas gerak mengalun, dari tari Pa'randing, henjutan tubuh dengan sikap kaki satu melangkah kemudian kaki lainnya mengikuti. Posisi tangan kiri ditekuk sejajar dada, torso sedikit condong ke arah depan, tangan kanan ditekuk dan diayunkan ke arah samping belakang dan ke arah depan dengan intensitas sedang sedikit bertenaga.

\section{Penari}

Penari merupakan sarana yang hidup, mampu mengobjektifkan subjektivitas konsep penata tari, tetapi penari harus tetap memiliki subjektivitas dalam interpretasinya. ${ }^{23}$ Untuk itu dipilih para penari yang memiliki pengalaman dalam berproses, memiliki tubuh dan postur yang sesuai dengan ide garapan, serta memiliki hubungan sosial yang baik dengan penata. Dengan demikian proses akan lebih lancar, penari akan lebih berani menyampaikan kritik atau sarannya sehingga teknik ketubuhan dapat ditampilkan dengan baik.

Petunjuk Praktis Bagi Guru, terjemahan Ben Soeharto, Yogyakarta, Ikalasti, 1985, p.16

${ }^{23}$ Y.Sumandiyo, 2011, Koreografi (Bentuk - Tehnik - Isi), Yogyakarta: Cipta Media, p.113 
Karya tari kelompok dengan tujuh penari, akan diolah sebagai berikut. Satu penari yang akan muncul pada bagian introduksi, juga merupakan penari inti, sebagai pengantar dengan menunjukkan motif-motif gerak yang ditarikan dalam garap inti. Bagian dua ditarikan oleh tujuh penari dengan pola rampak simultan dan saling mengisi simultan yang mengekspresikan kebersamaan dan kekuatan kerbau sebagai hewan kurban dalam Rambu Solo'. Bagian tiga dimulai dengan adegan adu kerbau hingga menuju adegan akhir menampilkan masyarakat Toraja menarikan tarian Ma'badong. Para penari yang dipilih memiliki postur tubuh yang tidak harus sama, namun lebih diutamakan memiliki kemampuan tubuh yang bisa mengikuti ketubuhan penata dari segi teknik dan bentuk, serta stamina yang baik untuk bisa menjiwai karakter gerak yang divisualisasikan. Desian gerak cenderung tegas, dengan kualitas kuat dan patah-patah.

\section{Musik Tari}

Pemilihan penata musik yang tepat harus melalui pertimbangan yang matang. Pertimbangan dilakukan untuk memprediksi kemungkinan garapan tari dan aspek-aspek iringan yang dibutuhkan untuk mewakili maksud dan tujuannya. Rancangan garapan tari ini membutuhkan iringan yang tidak hanya sekedar panutan tempo, tetapi juga sebagai perangsang imajinasi dan sentuhan emosi bagi penari dan penonton. Rangsang imajinasi tersebut diharapkan dapat membangun suasana pertunjukan, kebesaran, keagungan, kekuatan, dan tradisi Toraja.

Berkaitan dengan daerah asal penata dan ide dari karya ini yang sama-sama berasal dari Toraja Sulawesi Selatan, maka penata musik yang dipilih ialah penata musik yang samasama berasal dari Sulawesi Selatan dan telah menguasai jenis musik tradisional Sulawesi. Hal ini diharapkan akan mempermudah dalam proses penggarapan karya tari dan membangun sprit dari karya Garonto' Eanan. Alat musik yang digunakan ialah alat musik tradisional Toraja yaitu gendang, suling, dan beberapa alat musik non tradisi yaitu floor, bedug dan midi musik effect.

\section{Rias dan Busana}

Warna Busana kostum Garonto' Eanan dipilih warna hitam dengan diberi sentuhan kain tenun Toraja. Kostum ini terinspirasi dari tedong Tandirapasan yaitu julukan tedong atau kerbau hitam pilihan untuk upacara Sapurandanan (upacara Rambu Solo’ tingkatan paling tinggi). Bahan kain yang dipilih lebih bersifat fleksibel atau elastis seperti bahan spandek agar bisa dibuat press body, sehingga saat torso diliuk-liukkan akan tampak garis geraknya begitu juga ketika melakukan gerak dengan teknik yang cukup berat tidak mengganggu kenyamanan dalam bergerak. Rias karakter diwujudkan dengan mempertegas bagian mata, mulut, dan hidung 
JOGED

ISSN: 1858-3989

sehingga menghasilkan riasan wajah menyerupai hewan kerbau.

\section{Pemanggungan}

Karya Tari Garonto’ Eanan dipentaskan di proscenium stage Jurusan Tari Fakultas Seni Pertunjukan ISI Yogyakarta. Ruang yang digunakan berupa panggung berbentuk persegi panjang berwarna hitam yang memiliki sembilan ruang imajiner di dalamnya. Terdapat bingkai yang membatasi antara penonton dan penari. Ruang tersebut diolah sedemikian rupa hingga menghadirkan kesan imajinasi yang luas. Panggung tersebut dimanfaatkan sesuai dengan kaidah yang seharusnya, dan untuk kepentingan penyajian karya Garonto' Eanan, area panggung dibiarkan kosong tanpa set properti. Hal ini dipandang akan mempertegas tampilan tujuh penari yang dominan melakukan gerakan rampak simultan dan saling mengisi simultan dalam ragam formasi yang cenderung menyatu (focus on one point).

\section{PENUTUP}

\section{Gagasan karya Garonto' Eanan} bersumber dari pengalaman empiris saat terlibat langsung upacara Rambu Solo'. Karya ini mencoba memahami makna dan nilai hewan kerbau bagi masyarakat Toraja. Kerbau sebagai hewan kurban dalam Rambu Solo' memiliki pesan sosial yaitu kebersamaan dan rasa saling memiliki. Karya tari Garonto' Eanan yang berarti kerbau sebagai pokok harta
Robby Somba I KOREOGRAFI GARONTO' EANAN: ERBAU DALAM KEHIDUPAN MASYARAKAT TORAJA

benda, dipilih sebagai judul karya untuk menegaskan makna dan nilai hewan Kerbau dalam kehidupan masyarakat Toraja. Hewan Kerbau sebagai hewan kurban dalam upacara Rambu Solo', mempresentasikan status sosial dan penghormatan pada arwah.

Pelaksanaan ritual Rambu Solo' yang menghadirkan Kerbau sebagai pokok harta benda juga dipersepsikan mencerminkan makna kekuatan dan kebersamaan. Pemakanan terhadap peristiwa ini diusung sebagai tema tari Garonto' Eanan, diekspresikan melalui garap tari kelompok dengan tujuh penari putra. Ekspresi 'kebersamaan' dihadirkan melalui pengolahan formasi penari kelompok yang cenderung menyatu atau memusat, dan pengolahan terhadap gerak tari tradisional Toraja dalam pola rampak simultan dan saling mengisi simultan. Presentasi tradisi daerah Toraja melalui karya tari, dilakukan untuk menarik perhatian generasi muda agar tidak mengabaikan kesenian dan adat tradisional yang dimiliki.

\section{DAFTAR SUMBER ACUAN}

\section{A. Sumber Tertulis}

Departemen Pendidikan dan Kebudayaan. 1981-1982. Upacara Tradisional Daerah Sulawesi Selatan.

Hadi, Y.Sumandiyo. 2011. Koreografi (Bentuk - Tehnik - Isi). Yogyakarta:

Cipta Media 
2007. Kajian Tari Teks dan Konteks. Yogyakarta: Pustaka

Hawkins, Alma M. 1998. Creating Trought Dance. Terjemahan Y. Sumandiyo Hadi. 2003.

Mencipta Lewat Tari. Yogyakarta : Manthili.

Koentjaraningrat (2010). Manusia dan Kebudayan di Indonesia. Jakarta : Djambatan.

Kussudiardja, Bagong. 2000. Dari Klasik Hingga Kontemporer. Yogyakarta : Padepokan Press.

Marampa, A.T. 1983. Mengenal Toraja, Toraja: PT Sulo.

Martono, Hendro. 2010. Mengenal Tata Cahaya Seni Pertunjukan. Yogyakarta: Cipta Media.

Martono, Hendro. 2012. Ruang Pertunjukan dan Berkesenian. Yogyakarta : Cipta Media.

Meri, La. 1975. Dance Composition: The Basic Elements. Terjemahkan Soedarsono. 1986.

Komposisi Tari Elemen-Elemen Dasar. Yogyakarta: Lagaligo

Paseru, Seno. 2004. Aluk To Dolo Toraja (Upacara Pemakaman Masa Kini Masih SakraI). Salatiga: Widya Sari Press

Pasubang Gereja Toraja, 1996. Aluk Rambu Solo' (Upacara Kematian) dan Presepsi Kristen tentang Rambu Solo'. Tana Toraja : Percetakan Sulo Gereja Toraja

Sande, J.S, 1986. Badong Sebagai Lirik Kematian Masyarakat Toraja, Jakarta : Proyek Penerbitan Buku Sastra Indonesia dan Daerah.
Sarira. Y.A. 1996. Presepsi Orang Kristen Tentang Rambu Solo'. Rantepao: Pusbang Gereja Toraja.

Smith, Jacqueline, 1976, Dance Composition A Practical Guide for Teacher, London: Lepus Books. Terjemahan Ben Suharto, 1985, Komposisi Tari Sebuah Petunjuk Praktis bagi Guru, Yogyakarta : IKALASTI.

Soedarsono, R.M. 2002. Seni Pertunjukan Indonesia di Era Globalisasi. Jakarta : Direktorat Jendral Pendidikan Tinggi Departemen Pendidikan dan Kebudayaan.

Suhamihardja, Suhadi. 1977. Adat Istiadat dan Kepercayaan Sulawesi Selatan. Bandung : Litera

Tangdilintin, DR. HC. L.T. 1975. Upacara Pemakaman Adat Toraja, Tana Toraja: Yayasan Lepongan Bulan Book Publisher.

Tangdilintin, DR. HC. L.T, 2014. Toraja dan Kebudayaannya. Sulawesi Selatan: Lembaga Kajian dan Penulisan Sejarah Sulawesi Selatan.

\section{B. Narasumber}

Arnold Souisa, 27 tahun, guru Bahasa dan Seni di SMK Tagari Rantepao, juga memiliki kedudukan dalam masyarakat sebagai Ketua Adat.

\section{Discografi}

Muzakkir, Male Sau’ Puya, 2014 Karya Tugas Akhir Penciptaan Tari Pascasarjana berdurasi 50 menit. 
Robby Somba, Tandirapasan, 2017

Karya Koreografi Mandiri berdurasi 12 menit.

Eko Suprianto, Cry Jailolo, 2012

Durasi Karya 57 menit, Kuala

Lumpur Malaysia 